\title{
The Transition Of Graduates Of Vocational High Schools In The Digital Era
}

\author{
$1^{\text {st }}$ Arum Kartika Sari ${ }^{1}, 2^{\text {nd }}$ Putu Sudira ${ }^{2}$ \\ \{arumkartikasari@gmail.com ${ }^{1}$, putupanji@uny.ac.id² \\ Universitas Negeri Yogyakarta, Indonesia ${ }^{12}$
}

\begin{abstract}
Increased demand for labor in era 4.0 is expected to be in line with skilled digital-based graduates. VHS as one of the educational institutions prepares students to work with a short transition period. The research objective was to find out the time needed by VHS graduates in work, factors that influenced VHS graduates to quickly get jobs, and VHS graduate activities during the transition period. The study used ethnographic methods with the models of Miles and Huberman. The results of the study were graduate waiting times between 0,3 and 6 months. Factors that influence student waiting time are activeness, student achievement, work skills, strong desire to get work, parental encouragement, and economic factors. Use of the transition period by VHS students by finding job openings, preparing data to apply for jobs, submitting applications to job providers and waiting for job openings.
\end{abstract}

Keywords: Waiting Time, Transition, Vocational School Graduates

\section{Introduction}

One orientation of the implementation of vocational education is the adequacy of supply and demand for graduates towards employment. The International Labor Office (ILO) classifies a three-phase vocational education system that involves government and the private sector: 1) Unstructured and unregulated vocational education, where professional skills are obtained from the principle of apprenticeship; 2) the government determines who the profession and qualifications will be held, and 3) situations where the implementation of vocational education where all types of professions and qualifications are determined to meet the needs of the market economy [1].

Vocational education is education that provides students with certain skills to be able to work. In this case, prioritizing the development of skills and professional attitude towards students. In addition, vocational education invites someone to work effectively[2]. The scope of work is in the industry and outside the industry.

The purpose of VHS in addition to preparing students to be productive workforce needs to equip students in accordance with the times. In the millennial era students are expected to have abilities that follow the needs of industry 4.0. These needs include skills in the use of digital equipment, as well as technology-based communication [3].

Vocational education has the output of preparing students to work after graduation [4]. The output can be categorized as an entrepreneur or working in a company. In addition, 
graduates can continue their education to a higher level. In the digital era, vocational education does not only apply to core competencies. The ability to use digital-based is also needed. So that graduates have sufficient supplies.

In fact, not all graduates of vocational education can work after they graduate. Unemployment that occurs can be classified into several categories, namely: 1) waiting for the period of work calls from the industrial and business world; 2) in the process of applying for a job; 3) adding certain skills that are informal, or 4) graduates who are lazy to find work. Some of the factors that cause vocational school graduates unable to work directly in the industry are new certificates distributed after August. This has an impact on graduates who cannot register directly in the industry. Many students are not used to using the internet to see job openings [5]. Another factor is that employee recruitment is not carried out at any time. In addition, the cause of unemployment is made possible from the competency of VHS graduates who are not suitable. Limited employment is also one of the increasing unemployment rates.

An important driving factor that causes people to work is the need to be fulfilled. Activities in work contain elements of a social activity, produce something, and ultimately aim to meet their needs. However, behind these indirect goals, people work to get rewards in the form of wages or salaries of the results of his work. So, in essence, people work, not only to maintain their survival but also aim to achieve a better standard of living [6].

Currently to work does not only require adequate competence. However, the rapid development of the industrial world also needs to be considered [7]. Technological advances in the industrial world need to be owned by every graduate. The use of equipment with network systems, electronic devices, and the internet are needed to help workers [8]. If graduates do not have more skills in the digital field. Will result in decreased production capabilities with advanced systems.

Vocational school graduates who are accepted to work in the industrial world cannot directly work as employees in the company, but they must take part in training programs conducted by the company. The duration of training is between 3 and 6 months. In other words, students are considered permanent employees if they have finished participating in the training held by the company. In addition, students who want to work in leading companies must also have quality foreign language skills. Foreign languages are not only English but Japanese, Chinese, and German.

Based on the explanation above, it can be concluded that not all VHS graduates can work immediately after graduation. They choose to be unemployed until they get the right job. There are also those who choose to work even if they do not match the skills they have. If they have been accepted to work the next step is to conduct training for 3-6 months.

During the transition period, vocational school graduates, among others, attended training, some were unemployed. Some graduates undertook training due to several things. Like improving graduate competencies, increasing the confidence of graduates. In addition, graduates conduct training due to eliminating boredom.

Some graduates are also unemployed because they have not fulfilled the requirements required for existing job vacancies [9]. The many causes of unemployment in the community include: 1) lack of employment; 2) rapid population growth and not in accordance with the number of jobs available; 3) absence of matching wages received; 4) lack of information about job openings; 5) I want people who want to be entrepreneurs; 6) the work rate is not able to meet the quality desired by the world of work, and 7) the failure of the small industry sector and home industry in running their business. Factors that influence the transition period are soft skills, parents, teachers, and special job exchanges [10]. 
Soft skills can be seen from personal and interpersonal behaviors that can develop and maximize human performance (through training, developing teamwork, initiatives, another decision making. This soft skill is the basic capital of students to develop optimally according to their individual. This type of skill is part of a person's intellectual intelligence and is often used as a condition for obtaining certain positions or jobs, while parents influence the personality, attitude, and way of life of graduates, which is an indirect element of education that will automatically enter the person. children who are growing and developing. Parents have the responsibility to foster their children to be given education, love, and other needs so that later the child can become a responsible adult human.

Parental support can make their children ready to work [11]. Parental support is very important in making career choice decisions and readiness for children[12]. The narrative of several entrepreneurs in Historic[13], states that all family support received is the key to success. This explains that family support is very important to make the child succeed in work. The role of parents in this matter is very important to support work readiness. In addition, with the role of parents can develop attitudes that are in the affective domain such as increased creativity, accuracy, perseverance, or can provide apperception to their children.

Apart from parents, the school environment also affects the readiness of a student to work. Students who will graduate need career counseling to make it easier to get a job and consult the obstacles they experience when determining a career[14]. So that schools have the duties and responsibilities to provide a life for students. Therefore a teacher needs to make some changes to equip students to be ready to work.

The teacher is increasingly important to develop all the potential that exists through learning. From adaptive lessons are expected to produce graduates who can work directly in accordance with their expertise. Therefore, to find out how far the teacher in the formation of students' readiness to work requires several indicators. In this case, the necessary indicators include the teacher as a communicator, motivator, facilitator, inspirator.

Vocational High School graduates to get job information can be obtained through the Special Employment Exchange (SEE) in their respective schools. Work burdens are institutions that carry out their functions to bring together job seekers and labor users for work placements. The function of the SEE to bring together job seekers and labor users. SEE is in secondary education units, in tertiary education units and in training institutions that provide information on the labor market, registration of job seekers, providing counseling and job guidance and distribution and placement of job seekers.

\section{Research methods}

\subsection{Type of Research}

The research method used in this study is qualitative. The type of research approach is ethnography. This type of qualitative research with the ethnographic approach used in this study is intended to find information about the transition of vocational graduates before getting a job in the industrial world and the business world in accordance with the expertise they have.

\subsection{Research Settings and Analysis Unit}


This research was conducted on vocational school graduates who have worked in accordance with their competencies. The unit of analysis of this research is the waiting time needed by graduates of the vocational school to get a job, the factors that support vocational school graduates to get a job, and the things that vocational school graduates do to get a job. Data sources in interviews are vocational graduates who have worked.

\subsection{Data Collection Method}

Data collection methods used use in-depth interviews, participant observation and documentation assisted by a voice recorder. To improve the validity of the findings in this study verification of truth using triangulation method which includes combining various methods and subjects. The development of the instrument in this study uses the Mason model.

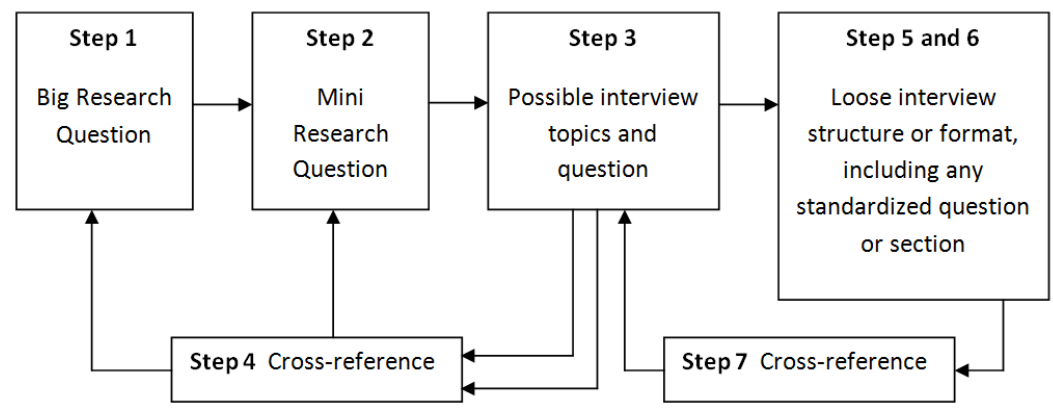

Fig. 1. Development of Mason Model Instruments[15]

\subsection{Validity and Data Analysis Techniques}

This study is to obtain the validity of data triangulation. In fulfilling the validity of the data, this study was triangulated with sources. Triangulation with sources means comparing and checking the degree of trust of information obtained through different time and tools in qualitative research. Triangulation with the sources conducted in this study is comparing the results of interviews with documents.

The data analysis technique used in this study is the Miles and Huberman model which includes reduction data, display data, and conclusions/verification. The data analysis scheme used in this study is presented as follows.

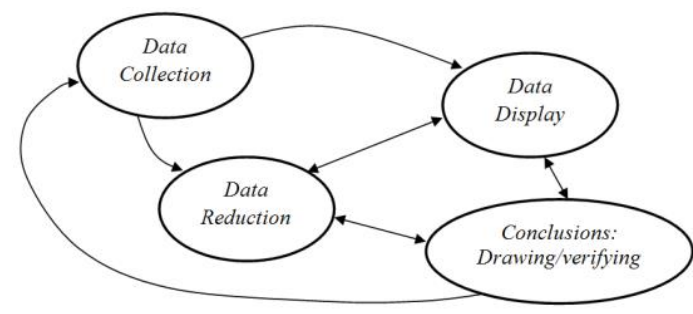

Fig. 2. Data Analysis Scheme Model Miles and Huberman[16] 
During the study took place in the field the three activities were carried out together and interrelated between one and the other. Then the meaning of the data obtained is done after the researcher leaves the field or place of research. Then the process of merging and uniformity of all forms of data obtained into one form of writing will be analyzed.

\section{Results and discussion}

\subsection{Research Results}

The names of respondents in the discussion were written using initials. This is intended to maintain the confidentiality or privatization of respondents to the public. As for the names needed in the data collected by researchers. Based on the research there are three objectives, but because the first, second, and third objectives are interrelated, the discussion is put together.

\subsubsection{Respondents Who Do Not Require Waiting Time (0 Months)}

Based on the results of the study, the first participant with code Dw and a second participant with code Drt respondents were respondents who did not require waiting time in finding a job, because after graduating and getting a diploma and vocational certificate they could immediately work. The work obtained by Dw and Drt is in accordance with the competency of their skills when they are in VHS.

In getting a job, Dw and Drt have several different factors that encourage them to get a job. Dw quickly got a job because he had a strong desire from himself and the world of work relations with the SEE in his Vocational High School. In terms of self-desire can be known from the effort he did to find a job before he graduated from vocational high school. These efforts include finding job information and entering job applications in several companies or workplaces.

In addition to getting information from the School Job Exchange (SJE) a strong desire from Dw's self to work can also be known by the choices he made, namely that he preferred to work rather than continue his studies. Dw's parents gave two choices, namely college or work. Although giving these two choices Dw's parents actually encouraged Dw to go to college before working because of Dw's two siblings, after graduating from high school, he continued his studies.

The same is true with parents and the teacher also advises Dw to continue his studies before working. While Drt was quick to get a job due to self-desire, parents' encouragement, the influence of teachers, and the world of work relations with SJE. Similarly, Dw in terms of self-desire Drt is looking for a job before he graduated from a vocational high school. These efforts include looking for job information and entering job applications at his place of Job Training JT first. In addition to the effort to find job information and submit job applications in his place of Job Training JT first, Drt also has self-motivation that if he has a job he will get experience in working and having his own income.

The factor of encouragement from parents is also a factor that influences Drt to get a job quickly. Here Drt's parents are very supportive and always give Drt's advice to be excited while looking for work and when Drt has worked. Suggestions from parents Drt is very beneficial for Drt, because Drt considers that the world of work is different from school and these suggestions make Drt focus and are passionate about doing his work where he works. 
The influence of teachers in Drt Vocational Schools is one factor that makes Drt quickly find a job. The influence of the teacher is shown by the provision of motivations before entering the workforce. Teachers who give the motivation to work are productive teachers and entrepreneurial subject teachers.

The SJE factor is one of the factors Drt quickly gets a job and works in a workplace that is in accordance with his area of expertise. According to Drt SJE always provide information relating to job openings, giving direction to each student to work in a field that is in accordance with their competence and provide recommendations for workplaces.

\subsubsection{Respondents who Need 3 Days Waiting Time}

Based on the results of the third participant with code $\mathrm{Tt}$, it takes 3 days after graduation to get the job and work he got in accordance with the competency of the skills taken when VHS. Tt quickly get a job because of the factors of self-desire, economic factors, factors of friends, and encouragement from parents. Your own desire to get a job quickly can be seen from Tt's attempt to immediately enter a vacancy at Delmora when she gets information that Delmora is opening a job. The explanation explains that in addition to self-desire, Tt gets a job because of factors from friends. Because $\mathrm{Tt}$ got this job vacancy information from a classmate.

Aside from self-desires and factors from friends, another factor that influences the speed at which Tt gets a job is from the encouragement of parents. Tt's parents are very supportive of Tt to work after graduating from VHS. Even though parents indirectly play an active role in finding a job Tt, but they always give support when Tt looks for work. Support provided by parents $\mathrm{Tt}$ in the form of direction and motivation. by parents $\mathrm{Tt}$ ie when choosing a job $\mathrm{Tt}$ should not work in a factory, because according to parents Tt works at the factory that does not know time and demands too much. Parents also direct when looking for work Tt should look for a job that is in accordance with his competence.

As for the factors of teachers of Vocational, Career Guidance, and Special Job Exchanges (SJE) Tt emphasized that these three factors were not factors that influenced him in finding a job and getting a job. Because according to $\mathrm{Tt}$ he got a job because of the information provided by his friend.

\subsubsection{Respondents who Need 2 Months of Waiting Time}

Based on the results of the research, the fourth participant with code Ry respondents took 2 months after graduating to get a job. Ry is just looking for a job after they graduate from vocational high school, in contrast to Dw, Drt, and Tt who have searched for and entered a job application before they graduated from vocational high school. The job that Ry gets is in accordance with the competency of the skills taken when VHS. After graduating from VHS, Ry gets a job because of the factors of self-desire, economic factors, factors of friends, parents' encouragement, and the influence of the teacher. Your own desire to get a job quickly can be seen from Ry's efforts to find job vacancies that he not only got from one source but from various sources. These sources of information come from schools, the internet, and friends.

Furthermore, Ry explained that he got information about job vacancies from the internet from the jobstreet.com website. Ry also explained that finding job vacancies through jobstreet.com is easier because many companies that require employees will post job openings to the web. The factor of encouraging parents is also a factor influencing Ry to quickly get a job. Ry's parents are very supportive and give Ry input when working must be painstaking and do not 
get bored quickly while working. In addition to support and motivation, Ry's parents also play a financial role when Ry is looking for work. Examples of Ry's parents' financial role are giving snacks, transportation costs, and other costs to meet the needs while looking for work.

\subsubsection{Respondents who Need 3 Months Waiting Time}

Based on the results of the research, the fifth participant with code Ov and a sixth participant with code and Ivn took 3 months after graduating to get a job. Similarly, respondents Ry, Ov and Ivn are just looking for work after they graduate from vocational high school. In getting a job, Ov and Ivn have several different factors that encourage them to get a job. Ov quickly gets a job because it has a strong desire from itself, encourages people old, the influence of the teacher, the relationship of the world of work with SJE, achievement, and economic factors. From the aspect of self-desire can be known from the effort that Ov did to find a job he graduated from VHS. These efforts include entering job applications and taking an entrance test to become a Sales Promotion Girl (SPG). Ov explained why he entered a job application and took the test to become SPG because according to Ov the most vacancies were vacancies to become SPG so he did not have another option to register as SPG, even though the job was not in accordance with his expertise.

Although Ov had tried to apply for a job and took the test to become an SPG, he did not qualify for the SPG test. In his journey, Ov got a job at a travel agent. Unlike the case with SPG, the job at the travel agent is in accordance with the skill competencies that he took while in the Vocational School, namely the Travel Business. Ov explained that he could work in the travel agent because when he was in school OvField Work Practice at the travel agent. When I was a Field Work Practice (FWP)Ov was offered by the travel agent's agent if he had passed Ov he could enter an application and work at the travel agent. After graduating from vocational high school, Ov was contacted by the travel agent's agent to work at the place, because Ov was not accepted as an SPG, he finally accepted the job.

The reason for choosing a travel agent where Ov works is to contact Ov to work at the place and not $\mathrm{Ov}$ who submits an application to the travel agent because of the good achievement Ov has when he does street vendors at the travel agent. This can be strengthened by the proof of the Certificate of FWP that Ov owns. The FWP certificate belonging to Ov explains that as long as Ov does FWP he gets the title of Good.

Aside from the Field Work Practice Certificate in the travel agent Raihan, the achievements that Ov has can be proven from the Field Work Practice Certificate as a Guide at Prambanan Temple. The certificate explained that as long as the street vendors as a guide at Prambanan Ov Temple received the title of Excellent.

Even though in getting a job Ov is offered directly by the travel agent's agent, but like a regular job applicant Ov still has to make a job application letter and attach the latest diploma, CV (Curriculum Vitae), and photo.

Ov also explained that in addition to these conditions, when he applied for a job at the travel agent there was no entrance test, namely a written test or an interview test as in other workplaces. Travel agents where Ov works do not carry out written tests or interview tests, probably because the travel agent is still an individual not in the form of a Limited Liability Company. Ov explained that when he first worked he immediately worked. Even though Ov went straight to work on the first day he entered work, the same as the other workplace travel agents where Ov worked also conducted training for new employees. Ov explained that the training he was taking was about three months. Ov explained that the training material he had done for three months was the same as the material he had obtained during school and there 
was no additional material. According to Ov, this is because the agent's travel owner is an alumnus of the 4 the vocational school majoring in Tourism, the same as the Ov school.

Ov added that the training carried out in the travel agent was not the addition of material or training that supported the work, but working was still under guidance and monitoring from the travel agent's owner. This is because according to Ov the travel agent's owner has not dared to call on jobs to serve customers to new employees. Ov also explained that the work he did at the travel agent was no different from the material he got when he was in vocational school first. The work that $\mathrm{Ov}$ is doing includes ticket resetting (airline tickets, ships, and trains) and making tour packages according to customer wishes.

Apart from self-desire and achievement, encouragement from parents is also a factor that influences Ov to get a job quickly. Ov's parents are very supportive and always motivate Ov to find work. Although Ov's parents initially suggested that Ov should go to college, but because Ov prefers to work wisely Ov's parents still give permission and support to the choice of the child.

Not only motivating, but butOv's parents also suggested that Ov works in a workplace that is in accordance with his competence and provides support by finding a job for Ov. The things that Ov's parents do to find a job are to find job vacancies from their friends and tell their friends if their children are looking for work, so if anyone needs employees, they can contact him.

In addition to parents, teachers in Ov schools also provide motivation so that when looking for work they look for workplaces that are in accordance with their skills and if they get a job that is not in accordance with expertise competencies that are not in line it is not a problem as long as they are able to do the job .

Ov also gets job vacancy information through the SJE in his Vocational School. According to the explanation, the information about job vacancies from SJE in Vocational Schools is usually shared through the device Whatsapp (WA) group and posted on job vacancy announcement boards in VHS. Besides going through WA group and posted on a notice board, SJE at VHS Ov also calls on students who need job information to direct and inform them of job vacancies.

Whereas Ivn got a job within three months after he graduated from vocational high school due to self-desire factors, economic factors, factors from friends, and parents' encouragement. Self-desire factors can be seen from the desire to get a job quickly because they do not want to bother the parents anymore. According to Ivn, if he got a job he would have his own money and would no longer bother his parents, which according to Ivn's explanation his parents' salary was not much.

When looking for a job, Ivn got a lot of information about job vacancies from friends and family. He explained that he got a lot of job vacancies from friends in the home because according to Ivn many friends in the house had worked. So that from his friends who have worked, Ivn gets a lot of information about job vacancies, for example, if at the place where his friend works are in need of a new employee he will tell Ivn that the place where he works is opening a job. Aside from friends Ivn also got information about job vacancies from her father and brother. The woman also explained that when she was looking for work her parents were very supportive. According to Ivn, her parents never demanded that she work in a workplace that was in line with the majors she took while in vocational. Ivn added that his parents always played an active role in giving support and giving motivation when he was looking for a job. The motivation given by his parents was very useful for him. The motivation was in finding a job. His job. In addition to providing support and motivation, Ivn's 
parents also provided facilities while he was looking for work. The facilities include giving gasoline and pocket money.

Furthermore, Ivn explained that in terms of the teacher, according to him, the teachers in his Vocational School did not provide information about job vacancies and what job directives suited him. This is because if Ivn wants to get directions from his teacher to get a job he must meet with the teacher personally and say it himself. Ivan himself never did this, so he did not get the information and direction from his teacher. When asked whether the Counseling Guidance(CG) teacher provided input and motivation to Ivn about the direction of work that was appropriate to him, Ivn explained that the CG teacher gave input and motivation but in a global scope and did not treat it individually. This is because the motivation and input are given during the lesson. Ivn added that if there are students who want to consult personally, they can meet with the counselor himself and the counselor will give counseling about a good career for the student. Ivn explained why he did not consult with the teacher about his career after graduation because Ivn was not interested in consulting and his close friends also did not consult. When asked if there was a career guidance in VHS, Ivan explained that there was career guidance in his school. want to do career guidance can directly meet and consult with the CG teacher.

Ivn also explained that to get information about job vacancies in his school there were also SJEIvn added that the SJE in his school provided information on job vacancies via notice boards and WA groups.

When asked what are the conditions he needed when applying for a job and whether there were any special requirements when applying for a job, he answered that there was no special requirement in Prabu Motor, whereas if at AVSEC there were some special requirements that had to be met. The conditions for applying for a job at Prabu Motor according to Ivn include a job application letter, having driver's license, photocopy of ID card, a copy of diploma, and photo. Whereas for special conditions that must be fulfilled at AVSEC are Indonesian citizens, maximum 28 years old, high school / vocational high school graduates, able-bodied, minimum height of $168 \mathrm{~cm}$ for men and $163 \mathrm{~cm}$ for women, not tattooed, not pierced, no glasses, no color blindness, and master a foreign language. Ivn further explained that the foreign language he must master is at least English. To get the English language requirements Ivn is not too difficult because Ivn has a little English.

Ivn explained that in all places he worked training for new employees. Training at Prabu Motor is conducted for 1 month, while in AVSEC it is conducted for 5 months and starts when you first enter work. The material that Ivn got during the training at Prabu Motor was nothing different from the material he had received while in VHS. While training materials at AVSEC include physical training, theory, and airport security.

Ivn explained that he worked at Prabu Motor for seven months when he applied for a job at AVSEC. When asked what was the reason he applied for a job at AVSEC, Ivn pointed out that he wanted to have new knowledge and get a bigger salary.

\subsubsection{Respondents who Need 6 Months of Waiting Time}

Based on the results of the research, the event participant with code Jhd respondents needed the longest time to get a job compared to other respondents. The time to get the job is 6 months after graduation. Jhd also explained that the work he got after graduating from one path with the department he took at VHS.

Jhd explained that what he did during his graduation until he got a job was to find job vacancy information and learn about computer programming. Jhd further explained that to increase his 
knowledge about computer programming he did not take any lessons. He got this knowledge through the community on the internet and Kaskus.

The factors that influence Jhd to get a job include self-interest factors, parents' motivation, and the internet. Self-desire to get a job quickly can be seen from Jhd efforts to find job vacancy information and deepen knowledge about programming.

Jhd also explained that when he was looking for work his parents were very supportive. Jhd also stated that in terms of providing input and suggestions on workplace suitable for Jhd, Jhd parents were not very active because according to Jhd his parents did not really understand computer science. Even so, Jhd parents were always active in motivating their children to not give up easily to get a job. Jhd added that his parents' support was very useful for him while looking for work. This support is in the form of material and moral support. In terms of material, Jhd's parents provide facilities in the form of computers, while in terms of morale, Jhd's parents always give motivation and prayers so that their children succeed in applying for jobs.

Furthermore, Jhd explained that in terms of teachers, according to him, the teachers in his vocational school did not play an active role in providing information on job openings. Jhd further explained that his students graduated, teachers and schools no longer provided information on job vacancies to their students.

When asked what are the conditions he needed when applying for a job, Ivn answered the conditions including job application letter, $\mathrm{CV}$, expertise competency, and active in the web question and answer forum provided by the company.

Ivn explained that at the place where he worked there was an internship for new employees. According to Jhd, the internship was conducted for six months. Training in the internship is carried out by learning by doing, that is, if there is an employee's duty to directly carry out the task and if anyone who does not understand the task will be directly guided by his mentor. The tasks given during training are network configuration and network topology. Jhd explained that in the training that he participated in, Jhd got a lot of material that he had never learned when he was in vocational schools, such as microtia programming and server building using the link.

Currently, Jhd is no longer working at the initial place he gets a job. Jhd explained that he worked at the first workplace for three and a half years. After leaving the workplace, Jhd prefers to entrepreneurship. Jhd prefers entrepreneurship and leaves the place to work because Jhd has known the technical problems of the computer network.

\subsection{Discussion}

\subsubsection{The amount of time needed to get a job}

Based on the results of the interview, it was found that there were variations in the length of time to get a job from 7 respondents. The variation is between the period of 0 months, 2 months, 3 months, and the longest are 6 months. Variation of getting a job invulnerable time 0 months here is interpreted after the respondent has passed the job immediately.

Respondents with the fastest time in getting a job are respondents with the initials Dw, Drt, and Tt. Respondents Dw, Drt, and Tt can be said to get the fastest job because within 0 months they have got a job. Dw and Drt respondents were immediately able to work after they graduated. While the Tt respondents got a job 3 days after he graduated.

Respondents with the initials Ry need 2 months to get a job. Respondents with initials Ov and Ivn get a job within 3 months. Respondents for the longest get a job are respondents with 
initials Jhd, that is, with the waiting time to get a job for 6 months. The range of VHS graduates in getting a job is no more than six months. This is because graduates work in an internship. Many graduates also diligently use social media to find out job information [17]. The use of cyber networks for search is very effective to be used by graduates [18]. Quickly the data needed can be seen.

\subsubsection{Factors Affecting Graduates of Vocational Schools Quickly Get Jobs}

Based on the results of the interviews the factors that influence respondents quickly get a job include self-desire to work, suspected economic factors, work world relations from SJE, factors from friends, parents' encouragement, and the influence of teachers.

Dw Respondents quickly got jobs because of the desire factor of themselves and the world of work relations from SJE. Tt respondents quickly got jobs because there were factors of selfdesire, economic factors, factors from friends, and encouragement from parents. Respondents Drt quickly got a job due to self-desire factors, factors from friends, parents' encouragement, and the influence of the teacher. Ry's respondents quickly got jobs because of their selfinterest factors, economic factors, work relations from SEE, factors from friends, parents' encouragement, and the influence of teachers. Ov respondents quickly got jobs because of their own personal desires, economic factors, factors influencing teachers, work relations with SEE, parents' achievements and encouragement. Jhd respondents quickly got jobs because of the factors of self-desire and factors from friends. Ivn respondents quickly got a job because of their own desire, economic factors, factors from friends, and parents' encouragement.

\subsubsection{Things that Graduates Do During Transition Time}

During the transition period the place to find work information, enter job applications, and conduct training can be helped using the internet. Graduates have already started to look at the internet to find the desired job [17]. besides that information from friends is also used to find out whether the job is feasible or not. During the three months of work, graduates also look for job information to get jobs according to their wishes. This is because during the internship the graduates feel less satisfied with the long job.

Some new students seek employment information and submit job applications after they graduate [18]. Not all students carry out work internships where they work. Before the work internship was finished many graduates had already gotten newer jobs. After graduating from VHS, several new students seeking employment information and entered the job application. The training is carried out at their workplace. The length of training is carried out for three to six months for the longest time.

\section{Conclusion}

1. The period or length of time required by vocational school graduates to get a job ranges from $0,2,3$ and 6 months after graduation. Work can be obtained by students who have achievements and are seen by business owners before students graduate or pre-graduate. When you get a job like this, on average you get it when you are an apprentice in the world of work or during industry practice and when you are finished the student is withdrawn to become a worker at the company. For the work waiting period of 0 , and 3 
months, the students who have persistence and a strong desire to get a job are obtained. Students like this use tricks: actively see the job market offered by the school, establish communication with graduates who are already working, and ask for direction from their teacher. The vocational high school students who need waiting time to get a job for 6 months are graduates who are waiting for an offer or obey the opportunities offered by the world of work.

2. Factors affecting the waiting period to get a job by vocational high school students are the liveliness of seeing the job market, student achievement, work skills during apprenticeship or industry practice, strong desire to get work opportunities, parents' encouragement, teacher encouragement, and economic factors.

3. The use of time during the transition by vocational high school students also varies, including finding job information, preparing the files needed to apply for a job, submitting an application to a job provider institution and waiting for job vacancies.

\section{References}

[1] R. C. W. Harold M. Byram, "Vocational Education and Practical Arts in the Community School," vol. 6, no. 7, p. 329, 1956.

[2] R. D. Hisrich, Entrepreneurship, 7th ed. New York: McGraw-Hill, 2008.

[3] M. Bali, "Digital Skills and Digital Literacy," Literacy today, no. February, pp. 24-25, 2016.

[4] Karina Mahirda and H. Wahyuni, "Returning To General And Vocational HighSchools In Indonesia,” vol. 9, no. 2, pp. 9-28, 2016.

[5] J. D. Becker and J. Dake, "Job Openings in Information Technology \& Decision Sciences: Home Brew Business Intelligence for Fun, Education and Maybe Even Profit," AMCIS 2011 Proc. - All Submissions, 2011.

[6] L. Kaminskiene, Social Partnership in Vocational Education and Training Lithuania: Challenges and Perspectives. Germany: Springer, 2009.

[7] A. Gelişli, Y., Beisenbayeva, L., Sultanbek, M. Z., Ussenova, "Vocational Education Systems In Turkey And The World: New Trends And Problems," Int. J. New Trends Educ. Their Implic., vol. 7, no. 3, pp. 1-10, 2016.

[8] A. Green, M. De Hoyos, Y. Li, and D. Owen, Job search study: literature review and analysis of the Labour Force Survey. London: Department for Work and Pensions, 2011.

[9] A. Bulfone, G., Fida, R., Vellone, E., Alvaro, R.,Palese, "Searching for a nursing job in an increased complexity of the labour market: An integrative review of the literature," J. Nurs. Educ. Pract., vol. 6, pp. 33-42, 2016.

[10] S. Bradley, "The School-to-Work Transition," in International Handbook of Education Economics, no. February, Cheltenham: Edward Elgar (Eds G. Jones and J. Jones), 2003, pp. 1-47.

[11] O. Isaac, "Effects of Parental Influence on Adolescents ' Career Choice in Badagry Local Government Area of Lagos State, Nigeria," J. Res. Method Educ., vol. 4, no. 4, pp. 44-57, 2014.

[12] S. Sarwar, "Influence of Parenting Style on Children's Behaviour," J. Educ. Educ. Dev., vol. 3, no. 2, p. 222, 2016.

[13] L. Kaminskiene, "Social Partnership in Vocational Education and Training Lithuania: 
Challenges and Perspectives," in International Handbook of Education for the Changing World of Work, Bridging Academic and Vocational Learning, Germany: Springer, 2009, pp. 261-275.

[14] N. Gautam, "A Study on Career Choice Related to Decision Making by Student," Int. J. Vocat. Educ. Training Res., vol. 3, no. 4, pp. 36-39, 2017.

[15] J. Mason, Qualitative Researching, 2nd ed. London: Sage Publication, 2002.

[16] M. B. Miles, \& Huberman, A. M., Qualitative Data Analyses. London: Sage Publication, Inc, 1994.

[17] B. J. Jansen, K. J. Jansen, and A. Spink, "Using the web to look for work: Implications for online job seeking and recruiting," Internet Res., vol. 15, no. 1, pp. 49-66, 2005.

[18] P. Kuhn and H. Mansour, "Is Internet Job Search Still Ineffective?," Econ. J., vol. 124, no. 581, pp. 1213-1233, 2014. 